\title{
The Effect of High Salt Intake on Endothelial Function: Reduced Vascular Nitric Oxide in the Absence of Hypertension
}

\author{
Matthew A. Boegehold \\ Department of Physiology and Pharmacology, West Virginia University School of Medicine, Morgantown, W.Va., USA
}

\author{
Key Words \\ Dietary salt · Endothelium · Nitric oxide $\cdot$ Reactive oxygen \\ species
}

\begin{abstract}
Within the last 25 years, it has become increasingly clear that high dietary salt intake represents a risk factor for the development of cardiovascular disease that is independent of its well-known ability to increase arterial pressure in some individuals. Studies in normotensive experimental animals and human subjects have revealed that a key feature of this pressure-independent effect of dietary salt is a profound reduction in vascular nitric oxide (NO) bioavailability that limits endothelium-dependent dilation. This reduction in NO is strongly associated with increased levels of reactive oxygen species (ROS) generated by NAD(P)H oxidase, xanthine oxidase or uncoupled endothelial NO synthase within the vascular wall, leading not only to scavenging of NO but also to disruption of some signaling pathways that mediate its production. The mechanistic link between high salt intake and elevated levels of enzymatically generated ROS in the peripheral vasculature is not clear, but a reduction in circulating angiotensin II may play a key role in this regard. Additional studies are needed to further elucidate the mechanisms, both at the systemic level and within the vascular wall, that trigger these salt-induced deficits in endothelial
\end{abstract}

function, and to further clarify how the attendant loss of NO may disrupt tissue blood flow regulation and ultimately lead to adverse cardiovascular events.

(c) 2013 S. Karger AG, Basel

\section{Introduction}

Although $\mathrm{Na}^{+}$is an essential micronutrient for the regulation of body fluid balance, maintenance of nerve and muscle function and a host of other fundamental physiological processes, average daily $\mathrm{Na}^{+}$intake greatly exceeds the estimated physiological need of $10-20 \mathrm{mmol} /$ day in virtually all cultures around the world [1]. The negative impact of high dietary salt on cardiovascular health has been well documented over many years, with arterial pressure recognized as a critical variable in this regard. It has been estimated that up to $50 \%$ of all individuals with essential hypertension are salt sensitive, i.e. their blood pressure is further increased by high salt intake and reduced by dietary salt restriction [2]. Because hypertension is a powerful predisposing factor for stroke, coronary artery disease and heart failure, its exacerbation by high salt intake further increases the risk of these and other adverse cardiovascular outcomes in such individuals $[3,4]$. However, it is now evident that high salt intake is also strongly associated with increased risk of 
cardiovascular disease and stroke independent of its effect on blood pressure [5-7]. Consistent with this recognition, it has become increasingly clear over the last 2 decades that high dietary salt intake, in the absence of hypertension, can lead to functional deficits in the vascular endothelium that are severe enough to limit the responsiveness of blood vessels to various vasomotor stimuli. The importance of this observation lies in the fact that endothelial dysfunction has been recognized as a precursor to and predictor of later cardiovascular disease in individuals with various cardiovascular risk factors [8-10].

This brief review will focus on the key studies (initially in animal models and more recently in human subjects) that have documented the extent to which high dietary salt intake can trigger endothelial dysfunction in peripheral vascular beds independent of any change in arterial pressure. Our current understanding of the cellular and molecular mechanisms that underlie these effects will be summarized in this context, and the functional effects of dietary salt on vascular smooth muscle will also be briefly described. Finally, critical areas for future investigation will be addressed.

\section{Animal Studies}

To explore the effect of increased salt intake on vascular function, investigators typically study animals that have been fed diets containing between 4 and $8 \% \mathrm{NaCl}$ by weight. There is little evidence of any differences among these diets in the magnitude of their effect on vascular function. Therefore, for the purposes of this review, any diet with an $\mathrm{NaCl}$ content between 4 and $8 \%$ will simply be referred to as a high salt diet, with no finer distinction made on the basis of actual salt content. $\mathrm{NaCl}$ content of the control diets used in these studies typically ranges between 0.1 and $0.8 \%$ by weight. These diets will be collectively referred to as 'low salt' diets.

The first experimental evidence to suggest that high salt intake can adversely affect endothelial function in the absence of increased arterial pressure was obtained from large conduit arteries. In 1987, Luscher et al. [11] reported that the normal ability of the endothelium to limit serotonin- or norepinephrine-induced constriction (through the release of nonspecific relaxing factors) is impaired in aortic rings from normotensive Dahl salt-resistant (Dahl-R) rats fed a high salt diet for 8 weeks. Soon after, Coyle [12] reported that the frequency of cerebral infarction after middle cerebral artery occlusion is dra- matically higher in normotensive Dahl- $\mathrm{R}$ rats fed a high salt diet for 3 weeks than in normotensive Dahl-R rats fed a low salt diet for the same duration. Because protection against infarction after such occlusion is largely dependent on the endothelium-dependent dilation of collateral vessels in response to increased flow [13], this finding suggests that high salt intake may have led to an impairment in endothelial shear stress responsiveness in these vessels.

The first evidence of an adverse effect of dietary salt on endothelial function at the microvascular level appeared in 1993, when Boegehold [14] reported that arteriolar dilation in response to the endothelium-dependent agonist acetylcholine $(\mathrm{ACh})$ was reduced in the spinotrapezius muscle of normotensive Dahl-R rats fed a high salt diet for 4 weeks. In that study, treatment with an L-arginine analog to inhibit nitric oxide (NO) synthase (NOS) reduced arteriolar diameters in Dahl-R rats fed a low salt diet but not in those fed the high salt diet, suggesting that the normal influence of endothelium-derived $\mathrm{NO}$ on resting vascular tone was lost in the animals fed high salt. In a follow-up study, the dilation of spinotrapezius muscle arterioles in response to acute increases in hemodynamic shear stress was attenuated after 2 weeks of high salt intake, apparently due to a selective loss of the NOmediated component of this dilation [15]. Since these initial findings in the spinotrapezius muscle, a blood pressure-independent effect of high salt intake on endothelial function has been documented in resistance vessels of other vascular beds, including the gracilis muscle [16], cremaster muscle [17-19], cerebral cortex [20] and mesentery [21, 22].

Studies involving pharmacological inhibition of NOS indicate that the overall contribution of $\mathrm{NO}$ to endothelium-dependent dilation is greatly diminished or lost altogether in rodents fed a high salt diet [15, 22-24]. However, the intrinsic responsiveness of vascular smooth muscles to NO, which was assessed by the use of various NO donor molecules, has been consistently found to be unchanged in these animals [14-20, 23-28]. Taken together, these findings suggest that high salt intake leads to a reduction in vascular NO bioavailability. Direct assessment of vascular wall NO levels by triazolofluorescein fluorescence has verified that both resting and stimulated NO levels are lower in conduit and resistance vessels from animals fed a high salt diet [21, 29-31]. This could reflect decreased NO production, increased NO breakdown or some combination of these two events. There is mounting evidence to suggest that NO is rapidly oxidized by reactive oxygen species (ROS) generated 
within the arteriolar wall in rats fed a high salt diet. We and others have found evidence of widespread oxidative stress in arterioles and venules of salt-fed rats and mice $[21,23-25,32,33]$, and treatment with superoxide dismutase (SOD) mimetics abolishes this oxidative stress and restores resting and stimulated NO levels to those measured in animals fed low salt diets $[21,23,25]$. These findings suggest that superoxide anion $\left(\mathrm{O}_{2}^{-}\right)$or one of its reactive products is responsible for the oxidation of $\mathrm{NO}$ under these conditions.

In addition to direct scavenging of NO, there is evidence to suggest that increased oxidant stress in vessels of animals fed a high salt diet can interfere with some endothelial cell signaling pathways that are required for endothelial NOS (eNOS) activation, leading to reduced NO production. Agonist-induced hyperpolarization of the endothelial cell membrane, a key event for increased NO production, is dramatically reduced in aortic segments of rats fed a high salt diet for 4 weeks, and this is due at least in part to impairment in intermediate-conductance $\mathrm{Ca}^{2+}$ sensitive $\mathrm{K}^{+}\left(\mathrm{IK}_{\mathrm{Ca}}\right)$ channels in the plasma membrane [34]. However, this impairment does not occur if the animals are simultaneously treated with an SOD mimetic throughout the period of high salt intake. Similarly, agonist-induced increases in endothelial cell $\mathrm{Ca}^{2+}$ levels, which are also important for eNOS activation, are attenuated in aortic segments from rats fed high salt for 3 days, and this effect is also prevented by chronic treatment with an SOD mimetic [31].

A number of studies have provided information on the enzymatic sources of $\mathrm{O}_{2}^{-}$in the vasculature of animals fed a high salt diet. Lenda and Boegehold [33] reported that oxidative stress in rat spinotrapezius muscle arterioles and venules following ingestion of a high salt diet is not associated with increased microvascular expression of $\mathrm{NAD}(\mathrm{P}) \mathrm{H}$ oxidase or xanthine oxidase, but pharmacological inhibition of these enzymes abolishes this oxidant stress, suggesting that their activity is responsible for $\mathrm{O}_{2}^{-}$production under these circumstances. Inhibition of $\mathrm{NAD}(\mathrm{P}) \mathrm{H}$ oxidase or xanthine oxidase also abolishes oxidant stress in mesenteric resistance arteries of rats fed a high salt diet [21]. In addition to $\mathrm{NAD}(\mathrm{P}) \mathrm{H}$ oxidase and xanthine oxidase, there may be other enzymatic sources of $\mathrm{O}_{2}^{-}$in the microvasculature of salt-fed animals, both under steady-state conditions and when the endothelium is acutely stimulated by agonists [33]. For example, uncoupled eNOS appears to be a major source of $\mathrm{O}_{2}^{-}$in spinotrapezius muscle arterioles of mice fed a high salt diet. Elevated steady-state $\mathrm{O}_{2}^{-}$levels in these vessels, as well as the ability of agonists to further increase these levels, is prevented by NOS inhibition with an L-arginine analog [23]. Reduced availability of tetrahydrobiopterin $\left(\mathrm{BH}_{4}\right)$, an essential cofactor for eNOS, is one of the primary causes of NOS uncoupling $[35,36]$, and this has been documented at the level of the arterioles in various pathological settings [37-39]. In a follow-up study on mouse spinotrapezius muscle, arteriolar wall $\mathrm{BH}_{4}$ levels were found to be almost $50 \%$ lower in animals with high salt intake than in those fed a normal diet [24]. An increased ratio of $\left[\mathrm{BH}_{2}\right] /\left[\mathrm{BH}_{4}\right]$ indicated that this was due to oxidation of $\mathrm{BH}_{4}$ rather than a decrease in its formation. When this $\mathrm{BH}_{4}$ oxidation was prevented by supplementing the high salt diet with L-arginine in the drinking water, arterioles showed no evidence of oxidant stress and the contribution of NO to endothelium-dependent dilation was completely preserved (fig. 1).

It is possible that $\mathrm{O}_{2}^{-}$production from $\mathrm{NAD}(\mathrm{P}) \mathrm{H}$ oxidase, xanthine oxidase, and in some cases eNOS, is increased in vessels of animals fed a high salt diet. Alternatively, at least with respect to sources other than eNOS, $\mathrm{O}_{2}^{-}$production may be normal but there is accumulation of $\mathrm{O}_{2}^{-}$because antioxidant defense mechanisms have been compromised under these conditions. Consistent with this latter possibility, studies in the spinotrapezius muscle and on isolated cerebral vessels indicate that high salt intake can lead to a reduction in vascular SOD expression and/or activity $[32,40]$.

The systemic events that link high dietary salt intake to a possible increase in oxidant generation and to decreased antioxidant enzyme activity in the vascular wall are not completely clear, but the reduction in plasma angiotensin II (Ang II) levels that normally accompanies increased salt intake may play a central role in this regard. This reduction in circulating Ang II is instrumental in increasing renal $\mathrm{Na}^{+}$and $\mathrm{H}_{2} \mathrm{O}$ excretion through multiple mechanisms (including reduced renal tubular $\mathrm{Na}^{+}$reabsorption), and as such represents an important physiological response to restore normal $\mathrm{Na}^{+}$ and $\mathrm{H}_{2} \mathrm{O}$ balance despite continued high salt intake [41]. However, prevention of this fall in circulating Ang II by intravenous infusion of Ang II at a subpressor concentration prevents the development of oxidant stress and the attendant reductions in NO bioavailability and endothelium-dependent dilation that would otherwise occur with high salt intake [21, 31, 42]. This may seem paradoxical, since numerous studies have documented that Ang II, acting through its $\mathrm{AT}_{1}$ receptor, can increase the production of $\mathrm{NAD}(\mathrm{P}) \mathrm{H}$ oxidase-generated $\mathrm{O}_{2}^{-}$in the vascular wall $[43,44]$. It is difficult to conceive of a mechanism that would act in the opposite direction, 


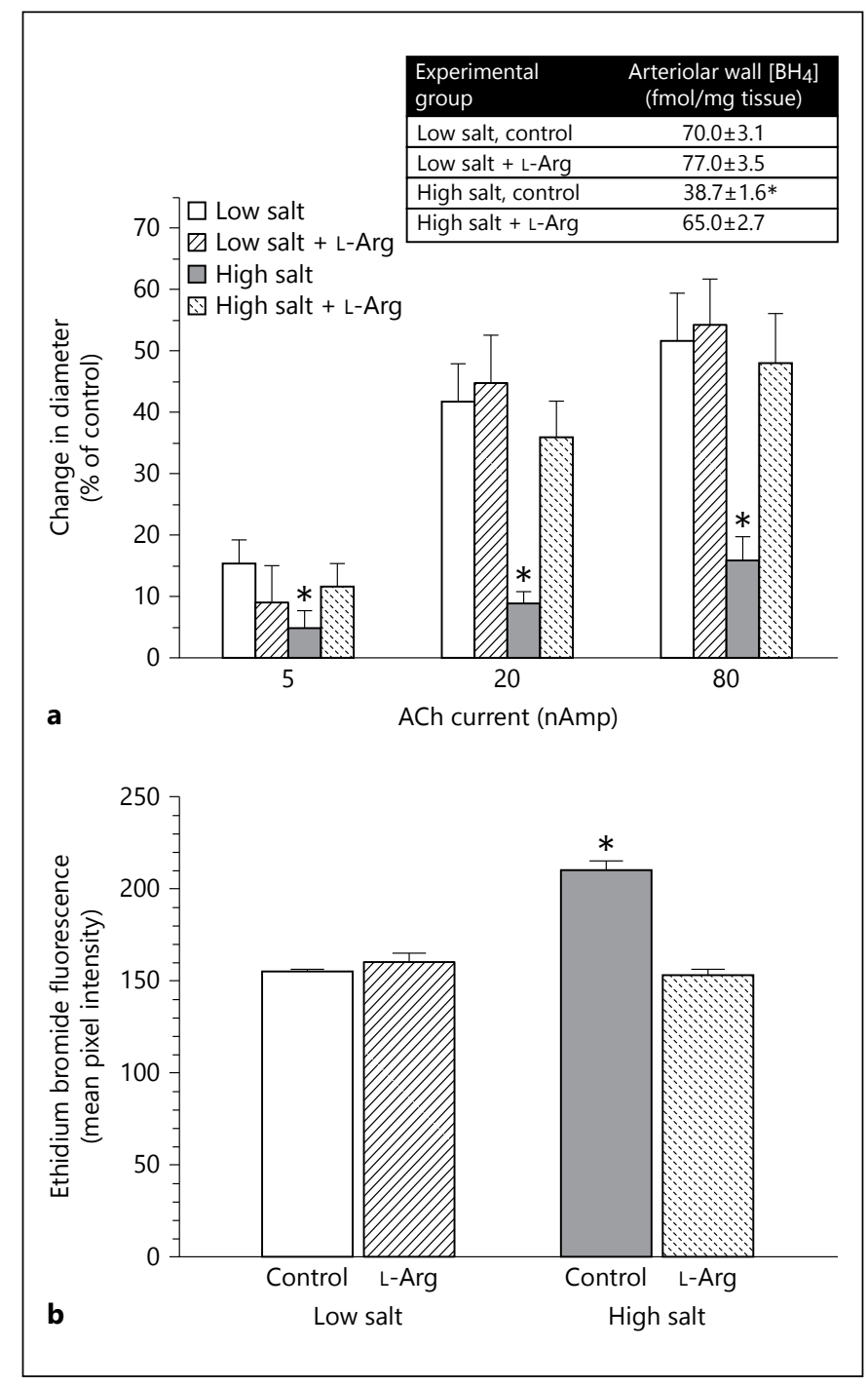

Fig. 1. a Arteriolar dilation in response to iontophoretic application of ACh to the spinotrapezius muscle of mice fed a low or high salt diet, with or without L-arginine (L-Arg) supplementation. Inset: $\mathrm{BH}_{4}$ levels measured by HPLC in arterioles from animals in each group. b Arteriolar wall ethidium bromide fluorescence (an index of $\mathrm{O}_{2}^{-}$levels) after exposure to hydroethidine in each experimental group. a, $\mathbf{b} * \mathrm{p}<0.05$ vs. low salt groups. Adapted from Nurkiewicz et al. [24], with permission.

such that a fall in circulating Ang II could trigger increased $\mathrm{O}_{2}^{-}$production. The elucidation of such a mechanism, if it does exist, would constitute an important advance in our understanding of the apparent concentration-dependent effect of Ang II on redox balance in the vascular wall. Alternatively, there is evidence to suggest that normal circulating levels of Ang II are critical for maintaining the normal expression and activity of vascular SOD $[45,46]$, and a recent report by Durand and Lombard [40] suggests that the oxidant stress associated with high salt intake is due to downregulation of SOD in direct response to the reduction in plasma Ang II levels.

Despite the strong evidence of reduced arteriolar NO levels in animals with high salt intake, we and others have consistently found that in vivo, the resting tone and inner diameters of these vessels are similar to those in animals fed low salt diets $[14,15,17,19,25,26]$, which is consistent with the absence of hypertension in the animals with high salt intake. This is presumably due to compensatory changes in the activity of other systems that regulate resting arteriolar diameter to ensure optimal tissue blood flow. However, this deficit in NO availability is likely to have functional consequences when the vasculature must respond to sudden hemodynamic or metabolic changes, possibly leading to a reduced capacity for local flow regulation.

\section{Human Studies}

Investigations on the impact of high salt intake on vascular behavior in humans have for the most part confirmed what has been learned from experimental animals, but due to their less invasive nature these studies have yielded less details on the mechanisms underlying salt-dependent changes in endothelial function than animal studies. Tzemos et al. [47] reported that in healthy male subjects subjected to 5 days of high salt intake, the increase in forearm blood flow triggered by intraarterial infusion of ACh is reduced by $27-37 \%$, and the effect of infused L-NMMA on resting forearm blood flow is reduced by $35 \%$. These observations are consistent with a reduction in both basal and stimulated vascular NO levels, but because the regimen of high salt intake used in this study also led to a small ( $3 \%)$ but significant increase in 24-hour ambulatory blood pressure, the effect of salt per se could not be conclusively separated from its effect on blood pressure. However, other studies have more clearly demonstrated a pressure-independent effect of high salt intake on endothelial function in humans. In healthy normotensive adults, Greaney et al. [48] reported that ingestion of a high $\mathrm{Na}^{+}$diet for 7 days had no significant effect on blood pressure, but reduced the dilator response of cutaneous arterioles to localized heating through a selective loss of the NO-dependent component of this dilation. In a subsequent study, these investigators reported that this same 7 -day high $\mathrm{Na}^{+}$regi- 
men had no effect on arterial pressure but reduced flow-mediated dilation of the brachial artery by an average of 30\% [49]. Flow-mediated dilation in human conduit arteries is mediated principally by endothelium-derived NO [50].

In humans, there may also be pronounced sex differences in the effect of dietary salt on endothelial function. In a study involving healthy cohorts of both men and women, ingestion of a high $\mathrm{Na}^{+}$diet for 5 days had no effect on arterial pressure but reduced the NO component of an ACh-induced increase in forearm blood flow by an average of 55\% [51]. Further analysis revealed that this overall decrease was due entirely to an effect in men, whereas in women the NO component of the dilation was insensitive to dietary salt. The mechanisms underlying this apparent sex difference and its implications for cardiovascular health in males versus females are not clear and warrant further study.

The human studies described above employed periods of high salt intake for only 5-7 days. In the animal studies described earlier, some investigators found marked changes in endothelial function after only 3 days on high salt $[16,21,30,31,52]$. However, a recent report on the postprandial effects of dietary salt has revealed that under some conditions increased salt intake can affect endothelial function on an even shorter time scale. In healthy, normotensive human subjects, flow-mediated dilation of the brachial artery was found to be significantly reduced for as long as 120 min after a single lowsalt meal, but this reduction was more pronounced at 30 and $60 \mathrm{~min}$ if the preceding meal had a higher salt content [53].

As in animals, the apparent decrease in vascular NO bioavailability following high salt intake in human subjects may be due to the accumulation of ROS in or near the vascular wall. Localized treatment with ascorbic acid, a nonspecific scavenger of ROS, completely restores the $\mathrm{NO}$-dependent component of arteriolar dilation to localized heating in individuals on a high salt diet [48]. However, there may also be a more direct effect of $\mathrm{Na}^{+}$on endothelial function in humans fed a high salt diet. Studies in human subjects have demonstrated that an increase in dietary $\mathrm{Na}^{+}$intake can produce an increase in plasma $\left[\mathrm{Na}^{+}\right]$of $2-4 \mathrm{mmol} / \mathrm{l}$ [54-56], and increases in $\mathrm{Na}^{+}$of this magnitude have been found to reduce eNOS activity and NO production in cultured human and bovine endothelial cells $[57,58]$. This mechanism, which would clearly be separate and distinct from the mechanism through which a reduction in circulating Ang II promotes endothelial dysfunction, might account for the rapid post- prandial effect of a high salt meal on flow-mediated dilation, although plasma $\left[\mathrm{Na}^{+}\right]$was not measured in that study [53]. However, this mechanism is not likely to be operative in rodents fed a high salt diet since plasma $\left[\mathrm{Na}^{+}\right]$apparently does not increase in these animals [59, $60]$.

In integrating the findings from both animal and human studies, a question that naturally arises is how the $\mathrm{Na}^{+}$content of diets used in animal studies compares with that of a typical human diet. A direct comparison of dietary $\mathrm{Na}^{+}$intake in rats versus humans may not be particularly useful due to pronounced differences in metabolism and electrolyte turnover rates between the two species. A more meaningful approach for comparing $\mathrm{Na}^{+}$intakes may be to consider the experimental intakes reached in rats and humans relative to the physiological $\mathrm{Na}^{+}$requirement for each species. The minimal physiological need for $\mathrm{Na}^{+}$in rats is somewhat controversial, but Brensilver et al. [61] has estimated that a minimal $\mathrm{Na}^{+}$intake of approximately $0.25 \mathrm{mmol} /$ day is required to sustain normal growth if caloric intake is sufficient. Taking into account the range of $\mathrm{Na}^{+}$contents for diets used in the rat studies cited above, and assuming that adult male Sprague-Dawley rats (typically used in these studies) consume 20-30 g of food per day $[62,63]$, estimated $\mathrm{Na}^{+}$intake would range from 0.34 to $4.17 \mathrm{mmol} /$ day for animals consuming the low salt diets and from 13.9 to $41.8 \mathrm{mmol} /$ day for animals consuming the high salt diets. Therefore, the high salt diets would have provided $\mathrm{Na}^{+}$at levels ranging from approximately 60 to 170 times the estimated minimal $\mathrm{Na}^{+}$requirement. In humans, under conditions of maximal renal $\mathrm{Na}^{+}$retention and without sweating, the minimal amount of $\mathrm{Na}^{+}$required to replace losses has been estimated at no more than $8 \mathrm{mmol} /$ day [64], with minimal requirements under more general conditions estimated to be $10-20 \mathrm{mmol} /$ day [1]. In comparison, around the world, average adult $\mathrm{Na}^{+}$consumption ranges from 100 to almost $300 \mathrm{mmol} /$ day [1], and $\mathrm{Na}^{+}$ consumption in the clinical studies cited above ranged from 300 to $400 \mathrm{mmol} /$ day [48-51], or approximately 40-50 times the estimated minimal $\mathrm{Na}^{+}$requirement. Clearly, in both rats and humans, the levels of $\mathrm{Na}^{+}$intake typically achieved in these studies grossly exceed physiological needs. However, as indicated above, average $\mathrm{Na}^{+}$intake for some human populations approaches these experimental levels, and it is reasonable to expect that some individuals within these populations could have $\mathrm{Na}^{+}$intakes in this experimental range, at least episodically. 


\section{Effect of a High Dietary Salt on Vascular Smooth Muscle}

The effects of high salt intake on the vasculature are not limited to the endothelium; complex changes in vascular smooth muscle function have also been documented in rats fed high salt. Studies carried out in both conduit and resistance vessels indicate that high salt intake can reduce the responsiveness of vascular smooth muscle to some vasodilator stimuli. For example, the dilation of skeletal muscle resistance arteries in response to a decrease in ambient oxygen levels and to the prostacyclin analog iloprost is greatly reduced by high salt intake, whereas responses to agonists that directly activate smooth muscle guanylyl cyclase or adenylyl cyclase are unaffected $[16,27,65]$. This indicates that the alterations are occurring upstream from these central elements in the signaling pathway, possibly at the level of smooth muscle membrane receptors and/or the G-protein coupling of these receptors to second messenger systems. The smooth muscle hyperpolarization that normally mediates these dilator responses is also decreased, or in some cases converted to depolarization, in vessels from rats fed high salt $[65,66]$. Additional mechanisms may be operative in other vascular beds. For example, the impairment of hypoxia-induced dilation in mesenteric resistance arteries from rats fed high salt appears to be the result of abnormally high production of 20-HETE (hydroxyeicosatetraenoic acid-) [67], a vasoconstrictor metabolite of cytochrome $\mathrm{P}_{450} 4 \mathrm{~A} \omega$-hydroxylase whose production in the vasculature is normally proportional to oxygen availability [68]. As with the oxidant-dependent deficits in endothelial function discussed above, some of these deficits in smooth muscle function are prevented if normal circulating levels of Ang II are preserved by continuous, low-dose Ang II infusion through a yet-to-be-clarified mechanism [27, 42 , 66].

High salt intake can also lead to a change in the responsiveness of vascular smooth muscles to some constrictor stimuli. Marvar et al. [69] have reported that arteriolar constriction in response to elevated ambient oxygen levels is decreased in the spinotrapezius muscle of rats with high salt intake, and that this is due to a decrease in the intrinsic responsiveness of arteriolar smooth muscle to 20-HETE. In contrast, high salt intake has no effect on arteriolar responsiveness to elevated oxygen levels in the cremaster muscle [52]. The difference between these two studies may be related to the duration of high salt intake; in the first study, rats were maintained on a high salt diet for 4 weeks, but in the second study rats were maintained on the high salt diet for only 3 days. Whereas a 3-day period of high salt intake is sufficient to trigger changes in vascular smooth muscle responsiveness to some stimuli $[18,27,66]$, this may not be the case for oxygen sensitivity. Myogenic constriction in response to acute increases in intravascular pressure can also be impaired in rats with high salt intake [26, 70-72]. Ang II, at concentrations below its vasoactive threshold, can potentiate the myogenic constriction of arterioles, in part through stimulation of signaling pathways that are common to both $\mathrm{AT}_{1}$-mediated and myogenic constriction [73]. The reduced myogenic responsiveness of spinotrapezius muscle arterioles in rats fed a high salt diet is largely due to the loss of this potentiating effect as plasma Ang II levels decrease, with a local increase in bradykinin, a vasodilator, also acting to modulate the myogenic constriction [71]. However, reduced myogenic behavior has not been observed in all vascular beds of rats fed a high salt diet [28]. Similarly, ingestion of a high salt diet also leads to an enhanced responsiveness to Ang II in some, but not all vascular beds $[28,69,71]$. The reasons for such regional heterogeneity in the effect of dietary salt on smooth muscle responsiveness to these, and likely other, constrictor stimuli are not clear.

\section{Conclusions and Areas of Future Investigation}

Studies carried out in both rats and mice fed high salt diets for up to 8 weeks indicate that elevated salt intake in the absence of an increase in arterial pressure leads to increased levels of enzymatically generated $\mathrm{O}_{2}^{-}$within the vascular wall. This leads to scavenging of endotheliumderived NO as well as a possible disruption of some endothelial cell signaling pathways that mediate its production. The cellular and subcellular events thought to be involved in this scenario are illustrated in figure 2. The resulting decrease in NO bioavailability is sufficient to severely compromise the endothelium-dependent regulation of vascular tone. Clinical studies have revealed that high dietary salt intake leads to similar endothelial dysfunction in humans, with some evidence to implicate oxidant stress as a causal factor in this setting, too. In many cases, these salt-dependent deficits in endothelial function are likely to be superimposed on complex functional changes in vascular smooth muscle, so that the overall effect of high salt intake on vascular behavior would reflect an integrated response to deficits at multiple sites.

Critical gaps remain in our understanding of the cellular and molecular events that underlie the development 


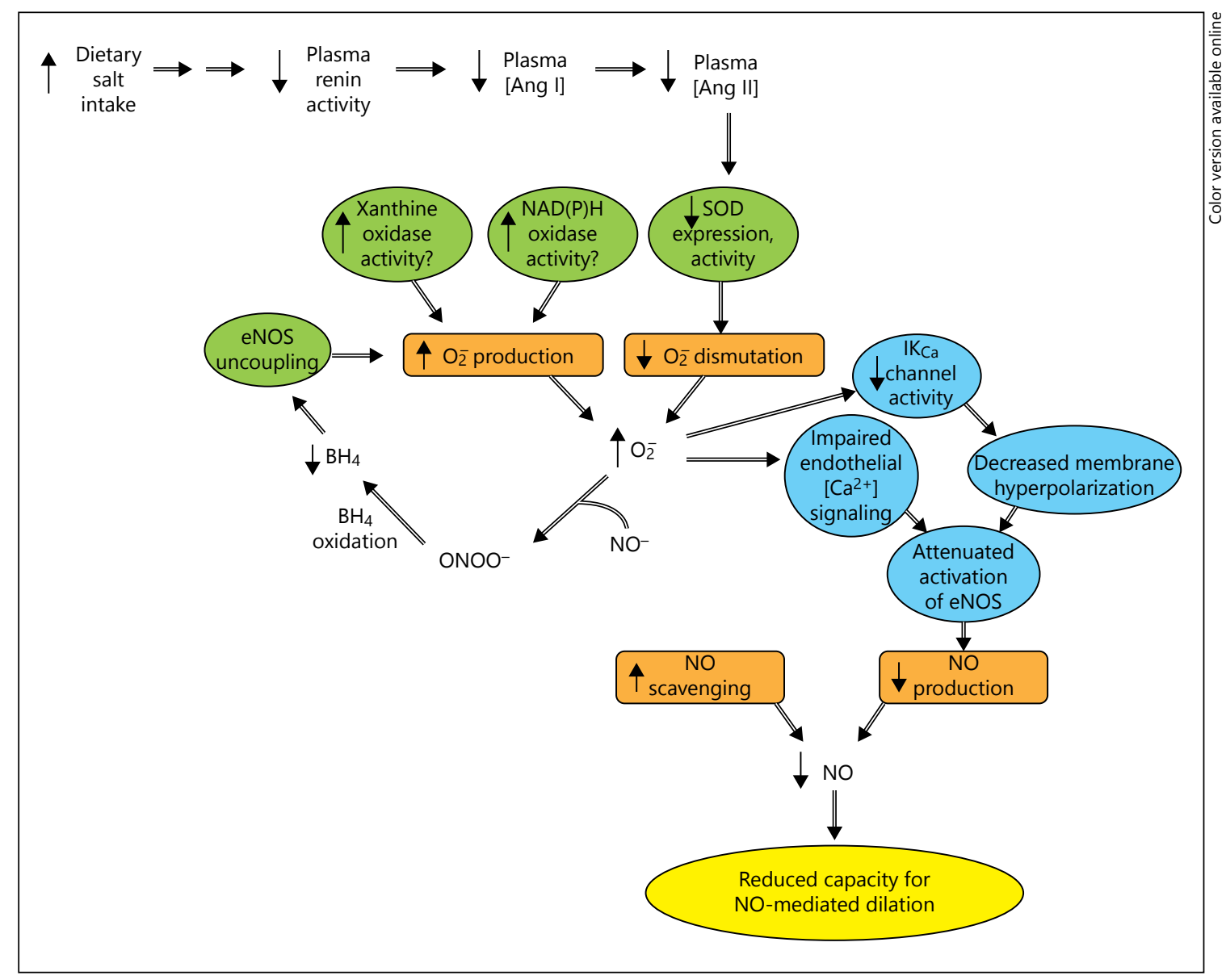

Fig. 2. Schematic diagram illustrating cellular and subcellular events that may contribute to reduced NO bioavailability in the peripheral vasculature following high dietary salt intake. A reduction in plasma Ang II levels plays a key role in linking increased salt intake to changes in the activity of oxidant and antioxidant enzymes in the vascular wall, although the details of this linkage are not well understood. $\mathrm{ONOO}^{-}=$Peroxynitrite.

of oxidant stress in the vascular wall after ingestion of a high salt diet, as well as our understanding of the effects of this oxidant stress on endothelial signaling pathways that are critical not only for NO generation, but also for the generation of other vasoactive factors that could modulate vascular tone. Additional investigation is also needed to more clearly define the humoral and/or neural mechanisms by which increased salt intake leads to increased $\mathrm{O}_{2}^{-}$levels in the vasculature, and specifically to provide more details concerning the role of reduced Ang II levels in promoting endothelial and smooth muscle dysfunction under these conditions.

Finally, in addition to the possible role of endothelial dysfunction as a pathological link between high salt intake and later development of cardiovascular disease [810], the combination of endothelial and smooth muscle deficits that develop in response to high salt intake may have a more acute effect on the regulation of tissue blood flow. The arteriolar dilation that permits an increase in blood flow when tissue metabolic demand is increased (i.e. active hyperemia) is a complex and incompletely understood process. Depending on the location of a vessel within the network, factors contributing to this dilation can include a fall in tissue oxygen levels $[74,75]$, a reduction in luminal pressure (leading to myogenic relaxation) $[76,77]$, and/or an increase in hemodynamic shear stress $[78,79]$. Since high salt intake may reduce arteriolar responsiveness to one or more of these stimuli $[15,26,69-$ $72]$, the arteriolar dilation and hyperemia that accompany an increase in metabolic activity could also be compromised under these conditions. Consistent with this possibility, Marvar et al. [80, 81] found that arteriolar di- 
lation in response to rhythmic contraction of the spinotrapezius muscle is reduced in rats fed a high salt diet. However, the magnitude of the attendant hyperemia was not reduced in these animals, suggesting that this reduced dilation may have been offset by increased dilation at some other level of the arteriolar network. Nevertheless, the possible effect of high salt intake on other forms of local flow regulation that involve these stimuli (e.g. autoregulation or reactive hyperemia) have not been assessed in the spinotrapezius muscle, and there have been no studies to assess the effect of high salt intake on flow regulation in any other vascular bed. These additional stud- ies are needed to more accurately determine the physiological consequences of high salt intake in peripheral vascular beds.

\section{Acknowledgments}

The author wishes to thank Kimberly Wix for her excellent technical assistance in many of the studies cited in this review. It was supported by National Institutes of Health grants HL-44012 and HL-52019, and by grants-in-aid from the American Heart Association, West Virginia Affiliate, and the American Heart Association, National Center (9750514N and 0150199N).

\section{References}

1 Brown I, Tzoulaki I, Candeias V, Elliott P: Salt intakes around the world: implications for public health. Int J Epidemiol 2009;38:791813.

12 Weinberger MH: Salt sensitivity of blood pressure in humans. Hypertension 1996;27: 481-490.

73 Campese VM: Salt sensitivity in hypertension. Renal and cardiovascular implications. Hypertension 1994;23:531-550.

$\checkmark 4$ Weinberger MH: Salt sensitivity is associated with an increased mortality in both normal and hypertensive humans. J Clin Hypertens 2002;4:274-276.

$>5$ He J, Ogden LG, Vupputuri S, Bazzano LA, Loria C, Whelton PK: Dietary sodium intake and subsequent risk of cardiovascular disease in overweight adults. JAMA 1999;282:20272034.

6 Strazzullo P, D’Elia L, Kandala NB, Cappuccio FP: Salt intake, stroke, and cardiovascular disease: meta-analysis of prospective studies. BMJ 2009;339:b4567.

-7 Tuomilehto J, Jousilahti P, Rastenyte D, Moltchanov V, Tanskanen A, Pietinen P, Nissinen A: Urinary sodium excretion and cardiovascular mortality in Finland: a prospective study. Lancet 2001;357:848-851.

-8 Brevetti G, Silvestro A, Schiano V, Chiariello $\mathrm{M}$ : Endothelial dysfunction and cardiovascular risk prediction in peripheral arterial disease: additive value of flow-mediated dilation to ankle-brachial pressure index. Circulation 2003;108:2093-2098.

-9 Schächinger V, Britten MB, Zeiher AM: Prognostic impact of coronary vasodilator dysfunction on adverse long-term outcome of coronary heart disease. Circulation 2000;101: 1899-1906.

10 Widlansky ME, Gokce N, Keaney JF, Vita JA Jr: The clinical implications of endothelial dysfunction. J Am Coll Cardiol 2003;42: 1149-1160.

11 Luscher TF, Raij L, Vanhoutte PM: Endothelium-dependent vascular responses in nor- motensive and hypertensive Dahl rats. Hy- -22 Raffai G, Durand MJ, Lombard JH: Acute pertension 1987;9:157-163.

12 Coyle P: High $\mathrm{NaCl}$ predisposes Dahl rats to cerebral infarction after middle cerebral artery occlusion. Hypertension 1988;12:96-101.

13 Dzau VJ, Gibbons GH: The role of the endothelium in vascular remodeling; in Rubanyi GM (ed): Cardiovascular Significance of Endothelium-Derived Vasoactive Factors. Mount Kisko, Futura, 1991.

14 Boegehold MA: Effect of dietary salt on arteriolar nitric oxide in striated muscle of normotensive rats. Am J Physiol 1993;264: H1810-H1816.

15 Boegehold MA: Flow-dependent arteriolar dilation in normotensive rats fed low- or high-salt diets. Am J Physiol 1995;269:H1407H1414.

-16 Liu Y, Fredricks KT, Roman RJ, Lombard JH: Response of resistance arteries to reduced $\mathrm{PO}_{2}$ and vasodilators during hypertension and elevated salt intake. Am J Physiol 1997; 273:H869-H877.

17 Frisbee JC, Lombard JH: Chronic elevations in salt intake and reduced renal mass hypertension compromise mechanisms of arteriolar dilation. Microvasc Res 1998;56:218-227.

18 Frisbee JC, Lombard JH: Acute elevations in salt intake and reduced renal mass hypertension compromise arteriolar dilation in rat cremaster muscle. Microvasc Res 1999;57:273283.

19 Frisbee JC, Lombard JH: Development and reversibility of altered skeletal muscle arteriolar structure and reactivity with high salt diet and reduced renal mass hypertension. Microcirculation 1999;6:215-225.

20 Liu Y, Rusch NJ, Lombard JH: Loss of endothelium and receptor-mediated dilation in pial arterioles of rats fed a short-term high salt diet. Hypertension 1999;33:686-688.

21 Zhu J, Huang T, Lombard JH: Effect of highsalt diet on vascular relaxation and oxidative stress in mesenteric resistance arteries. J Vasc Res 2007;44:382-390. and chronic angiotensin-(1-7) restores vasodilation and reduces oxidative stress in mesenteric arteries of salt-fed rats. Am J Physiol Heart Circ Physiol 2011;301:H1341H1352.

23 Nurkiewicz TR, Boegehold MA: High salt intake reduces endothelium-dependent dilation of mouse arterioles via superoxide anion generated from nitric oxide synthase. Am J Physiol Regul Integr Comp Physiol 2007; 292:R1550-R1556.

24 Nurkiewicz TR, Wu G, Li P, Boegehold MA: Decreased arteriolar tetrahydrobiopterin is linked to superoxide generation from nitric oxide synthase in mice fed high salt. Microcirculation 2010;17:147-157.

25 Lenda DM, Sauls BA, Boegehold MA: Reactive oxygen species may contribute to reduced endothelium-dependent dilation in rats fed high salt. Am J Physiol 2000;279:H7-H14.

26 Nurkiewicz TR, Boegehold MA: Limitation of arteriolar myogenic activity by local nitric oxide: segment-specific effect of dietary salt. Am J Physiol Heart Circ Physiol 1999;277:H1946H1955.

27 Weber DS, Lombard JH: Elevated salt intake impairs dilation of rat skeletal muscle resistance arteries via ANG II suppression. Am J Physiol Heart Circ Physiol 2000;278:H500H506.

28 Weber DS, Frisbee JC, Lombard JH: Selective potentiation of angiotensin-induced constriction of skeletal muscle resistance arteries by chronic elevations in dietary salt intake. Microvasc Res 1999;57:310-319.

29 Sylvester FA, Stepp DW, Frisbee JC, Lombard $\mathrm{JH}$ : High-salt diet depresses acetylcholine reactivity proximal to NOS activation in cerebral arteries. Am J Physiol Heart Circ Physiol 2002;283:H353-H363.

30 Zhu J, Mori T, Huang T, Lombard JH: Effect of high-salt diet on NO release and superoxide production in rat aorta. Am J Physiol 2004;286:H575-H583. 
-31 Zhu J, Drenjancevic-Peric I, McEwen S, Friesema J, Schulta D, Yu M, Roman RJ, Lombard JH: Role of superoxide and angiotensin II suppression in salt-induced changes in endothelial $\mathrm{Ca}^{2+}$ signaling and $\mathrm{NO}$ production in rat aorta. Am J Physiol Heart Circ Physiol 2006;291:H929-H938.

- 32 Lenda DM, Boegehold MA: Effect of a high salt diet on microvascular antioxidant enzymes. J Vasc Res 2002;39:41-50.

33 Lenda DM, Boegehold MA: Effect of a high salt diet on oxidant enzyme activity in skeletal muscle microcirculation. Am J Physiol Heart Circ Physiol 2002;282:H395-H402.

- 34 Bondarenko A, Panasiuk O, Stepanenko L, Goswami N, Sagach V: Reduced hyperpolarization of endothelial cells following high dietary $\mathrm{Na}^{+}$: effects of enalapril and tempol. Cli Exp Pharmacol Physiol 2012;39:608-613.

- 35 Hong H-J, Hsiao G, Cheng T-H, Yen M-H: Supplementation with tetrahydrobiopterin suppresses the development of hypertension in spontaneously hypertensive rats. Hypertension 2001;38:1044-1048.

-36 Vásquez-Vivar J, Kalyanaraman B, Martasek P, Hogg N, Masters BS, Karoui H, Tordo P, Pritchard KA: Superoxide generation by endothelial nitric oxide synthase: the influence of cofactors. Proc Natl Acad Sci USA 1998;95: 9220-9225.

-37 Bagi Z, Koller A: Lack of nitric oxide mediation of flow-dependent arteriolar dilation in type I diabetes is restored by sepiapterin. J Vasc Res 2003;40:47-57.

- 38 Cherng TW, Paffett ML, Jackson-Weaver O, Campen MJ, Walker BR, Kanagy NL: Mechanisms of diesel-induced endothelial nitric oxide synthase dysfunction in coronary arterioles. Environ Health Perspect 2011;119:98103.

-39 Sun H, Patel KP, Mayhan WG: Tetrahydrobiopterin, a cofactor of NOS, improves endothelial dysfunction during chronic alcohol consumption. Am J Physiol Heart Circ Physiol 2001;281:H1863-H1869.

40 Durand MJ, Lombard JH: Low-dose angiotensin II infusion restores vascular function in cerebral arteries of high salt-fed rats by increasing copper/zinc superoxide dimutase expression. Am J Hypertens 2013;26:739747.

41 McDonough AA: Mechanisms of proximal tubule sodium transport regulation that link extracellular fluid volume and blood pressure. Am J Physiol Regul Integr Comp Physiol 2010;298:R851-R861.

42 McEwen ST, Schmidt JR, Somberg L, de la Cruz L, Lombard JH: Time-course and mechanisms of restored vascular relaxation by reduced salt intake and angiotensin II infusion in rats fed a high-salt diet. Microcirculation 2009; 16:220-234

-43 Rajagopalan S, Kurz S, Munzel T, Tarpey M, Freeman BA, Griendling KK, Harrison DG: Angiotensin II-mediated hypertension in the rat increases vascular superoxide production via membrane NADH/NADPH oxidase activation. Contribution to alterations of vasomotor tone. J Clin Invest 1996;97:19161923.

44 Seshiah PN, Weber DS, Rocic P, Valppu L, Taniyama Y, Griendling KK: Angiotensin II stimulation of $\mathrm{NAD}(\mathrm{P}) \mathrm{H}$ oxidase activity: upstream mediators. Circ Res 2002;91:406-413.

45 Fukai T, Siegfried MR, Ushio-Fukai M, Griendling KK, Harrison DG: Modulation of extracellular superoxide dismutase expression by angiotensin II and hypertension. Circ Res 1999;85:23-28.

46 Gongora MC, Qin Z, Laude K, Kim HW, McCann L, Folz JR, Dikalov S, Fukai T, Harrison DG: Role of extracellular superoxide dismutase in hypertension. Hypertension 2006; 48:473-481.

47 Tzemos N, Lim PO, Wong S, Struthers AD, MacDonald TM: Adverse cardiovascular effects of acute salt loading in young normotensive individuals. Hypertension 2008;51:15251530 .

48 Greaney JL, DuPont JJ, Lennon-Edwards SL, Sanders PW, Edwards DG, Farquhar WB: Dietary sodium loading impairs microvascular function independent of blood pressure in humans: role of oxidative stress. J Physiol 2012;590:5519-5528.

49 DuPont JJ, Greaney JL, Wenner MM, Lennon-Edwards SL, Sanders PW, Farquhar WB, Edwards DG: High dietary sodium intake impairs endothelium-dependent dilation in healthy salt-resistant humans. J Hypertens 2013;31:530-536

50 Joannides R, Haefeli WE, Linder L, Richard V, Bakkali EH, Thuillez C, Lüscher TF: Nitricoxide is responsible for flow-dependent dilatation of human peripheral conduit arteries in vivo. Circulation 1995;91:1314-1319.

-51 Eisenach JH, Gullixson LR, Kost SL, Joyner MJ, Turner ST, Nicholson WT: Sex differences in salt sensitivity to nitric oxide dependent vasodilation in healthy young adults. J Appl Physiol 2012;112:1049-1053.

52 Frisbee JC, Falck JR, Lombard JH: Contribution of cytochrome P-450 $\omega$-hydroxylase to altered arteriolar reactivity with high-salt diet and hypertension. Am J Physiol Heart Circ Physiol 2000;278:H1517-H1526.

53 Dickinson KM, Clifton PM, Keogh JB: Endothelial function is impaired after a high-salt meal in healthy subjects. Am J Clin Nutr 2011; 93:500-505.

54 Johnson AG, Nguyen TV, Davis D: Blood pressure is linked to salt intake and modulated by the angiotensinogen gene in normotensive and hypertensive elderly subjects. J Hypertens 2001;19:1053-1060.

55 Sagnella GA, Markandu ND, Buckley MG, Miller MA, Singer DR, MacGregor GA: Hormonal responses to gradual changes in dietary sodium intake in humans. Am J Physiol 1989; 256:R1171-R1175.

56 Sullivan JM, Ratts TE, Taylor JC, Kraus DH, Barton BR, Patrick DR, Reed SW: Hemodynamic effects of dietary sodium in man. Hypertension 1980;2:506-514.
57 Li J, White J, Guo L, Zhao X, Wang J, Smart EJ, Li XA: Salt inactivates endothelial nitric oxide synthase in endothelial cells. J Nutr 2009;139:447-451.

58 Oberleithner H, Riethmüller C, Schillers H, MacGregor GA, de Wardener HE, Hausberg M: Plasma sodium stiffens vascular endothelium and reduces nitric oxide release. Proc Natl Acad Sci USA 2007;104:1628116286.

59 Nakamura K, Cowley AW Jr: Sequential changes of cerebrospinal fluid sodium during the development of hypertension in Dahl rats. Hypertension 1989;13:243-249.

60 Qi N, Rapp JP, Brand PH, Metting PJ, Britton SL: Body fluid expansion is not essential for salt-induced hypertension in SS/Jr rats. Am J Physiol 1999;277:R1392-R1400.

61 Brensilver JM, Daniels FH, Lefavour GS, Malseptic RM, Lorch JA, Ponte ML, Cortell S: Effect of variations in dietary sodium intake on sodium excretion in mature rats._Kidney Int 1985;27:497-502.

62 Vento PJ, Swartz ME, Martin LB, Daniels D: Food intake in laboratory rats provided standard and fenbendazole-supplemented diets. J Am Assoc Lab Anim Sci 2008;47:4650.

63 Keenan KP, Ballam GC, Dixit R, Soper KA, Laroque P, Mattson BA, Adams SP, Coleman JB: The effects of diet, overfeeding and moderate dietary restriction on Sprague-Dawley rat survival, disease and toxicology. J Nutr 1997; 127:851S-856S.

64 Franco V, Oparil S: Salt sensitivity, a determinant of blood pressure, cardiovascular disease and survival. J Am Coll Nutr 2006;25:247S255S.

65 Frisbee JC, Sylvester FA, Lombard JH: Highsalt diet impairs hypoxia-induced cAMP production and hyperpolarization in rat skeletal muscle arteries. Am J Physiol Heart Circ Physiol 2001;281:H1808-H1815.

66 Lombard JH, Sylvester FA, Phillips SA, Frisbee JC: High-salt diet impairs vascular relaxation mechanisms in rat middle cerebral arteries. Am J Physiol Heart Circ Physiol 2003; 284:H1124-H1133.

67 Wang J, Roman RJ, Falck JR, de la Cruz L, Lombard JH: Effects of high-salt diet on CYP450-4A omega-hydroxylase expression and active tone in mesenteric resistance arteries. Am J Physiol Heart Circ Physiol 2005; 288:H1557-H1565.

68 Harder DR, Narayanan J, Birks EK, Liard JF, Imig JD, Lombard JH, Lange AR, Roman RJ: Identification of a putative microvascular oxygen sensor. Circ Res 1996;79:54-61.

69 Marvar PJ, Falck JR, Boegehold MA: High dietary salt reduces the contribution of 20 HETE to arteriolar oxygen responsiveness in skeletal muscle. Am J Physiol Heart Circ Physiol 2007;292:H1507-H1515.

70 Nurkiewicz TR, Boegehold MA: High dietary salt alters arteriolar myogenic responsiveness in normotensive and hypertensive rats. Am J Physiol 1998;275:H2095-H2104. 
71 Nurkiewicz TR, Boegehold MA: Reinforcement of arteriolar myogenic activity by endogenous ANG II: susceptibility to dietary salt. Am J Physiol Heart Circ Physiol 2000; 279:H269-H278.

72 Takenaka T, Forster H, De Micheli A, Epstein M: Impaired myogenic responsiveness of renal microvessels in Dahl salt-sensitive rats. Circ Res 1992;71:471-480.

73 Kirton CA, Loutzenhiser R: Alterations in basal protein kinase $\mathrm{C}$ activity modulate renal afferent arteriolar myogenic reactivity. Am J Physiol 1998;275:H467-H475.

74 Lash JM, Bohlen HG: Perivascular and tissue $\mathrm{PO}_{2}$ in contracting rat spinotrapezius muscle. Am J Physiol 1987;252:H1192H1202.
75 Sparks HV Jr: Effect of local metabolic factors on vascular smooth muscle; in Bohr DF, Somlyo AP, Sparks HV Jr (eds): Handbook of Physiology. The Cardiovascular System, vol II: Vascular Smooth Muscle. Bethesda, American Physiological Society, 1980, pp 475-513.

76 Kuo L, Chilian WM, Davis MJ: Interaction of pressure- and flow-induced responses in porcine coronary resistance vessels. Am J Physiol 1991;261:H1706-H1715.

77 Kuo L, Davis MJ, Chilian WM: Longitudinal gradients for endothelium-dependent and -independent vascular responses in the coronary microcirculation. Circulation 1995; 92:518-525.
78 Bohlen HG, Nase GP: Dependence of intestinal arteriolar regulation on flow-mediated nitric oxide formation. Am J Physiol Heart Circ Physiol 2000;279:H2249-H2258.

79 Pohl U, de Wit C, Gloe T: Large arterioles in the control of blood flow: role of endothelium-dependent dilation. Acta Physiol Scand 2000;168:505-510.

80 Marvar PJ, Nurkiewicz TR, Boegehold MA: Reduced arteriolar responses to skeletal muscle contraction after ingestion of a high salt diet. J Vasc Res 2005;42:226-236.

81 Marvar PJ, Hammer LW, Boegehold MA: Hydrogen peroxide-dependent arteriolar dilation in contracting muscle of rats fed normal and high salt diets. Microcirculation 2007;14: 779-791. 